\title{
REPENSANDO A ESPINOSA: \\ SU PAPEL EN LOS DEBATES SOBRE LA REIVINDICACIÓN ESTÉTICA DEL CUBISMO Y LA PRODUCCIÓN PLÁSTICA DE PICASSO EN EL CONTEXTO CULTURAL CANARIO \\ $(1920-1930)^{*}$
}

\author{
Beatriz Martínez López \\ Instituto de Historia, CSIC, Madrid
}

\section{RESUMEN}

El presente estudio pretende reflexionar en torno al papel que Agustín Espinosa jugó en la reivindicación del cubismo y de la figura de Pablo Ruiz Picasso durante el primer tercio del siglo xx español. Para ello se parte del análisis filológico e historiográfico de Gaceta de Arte de Tenerife, órgano de difusión de la renovación artístico-cultural en España. La interpretación picassiana de la revista tinerfeńa bebe del discurso surrealista parisino, encabezado por André Breton, así como de una serie de precedentes literarios presentes en el ámbito insular ya en la década de 1920. Al profundizar en la obra de Espinosa es posible formular nuevos planteamientos relacionales entre las imágenes literarias del poeta canario y las dinámicas de creación y defensa del cubismo.

Palabras clave: vanguardia canaria, cubismo, surrealismo, Agustín Espinosa, Picasso.

RETHINKING ESPINOSA: HIS ROLE IN THE DEBATES

ON THE AESTHETIC VINDICATION OF CUBISM AND PICASSO'S ART

IN THE CANARIAN CULTURAL CONTEXT (1920-1930)

\section{Abstract}

This study aims to reflect on the role Agustín Espinosa played in the vindication of both Cubism and the figure of Pablo Ruiz Picasso during the first third of the Spanish 20th century. To this end, it starts from a philological and historiographical analysis of Tenerife Gaceta de Arte, vehicle of dissemination of the artistic and cultural renewal in Spain. In this sense, the Picassian discourse of the Tenerife magazine is based on the Parisian surrealist group, headed by André Breton, as well as on a series of literary precedents present in the Canary Islands in the 1920s. When deepening into Espinosa's work, it is possible to formulate new relational approaches between the literary images of the Canary poet and the Cubist dynamics, together with the defence of the movement.

Keywords: Canary avant-garde, cubism, surrealism, Agustín Espinosa, Picasso. 


\section{UN NUEVO PARADIGMA: SITUACIÓN DEL PANORAMA ARTÍSTICO EN LA ESPAÑA PREBÉLICA}

A ritmo desacompasado, aunque con una ambición similar, el panorama artístico español de las décadas previas al estallido de la guerra civil fue, al igual que había ocurrido en el ámbito europeo, objeto de numerosas transformaciones. La crítica artística, especialmente sensible a estos cambios a finales de los años veinte, adquirió un triple propósito que, en palabras de M. ${ }^{a}$ Isabel Cabrera, implicaba «el compromiso con la modernidad, lo europeo, lo internacional; [...] el compromiso con lo autóctono, la tradición y lo español, y [...] el compromiso del arte y la cultura con la política y la ideología» (Cabrera 2008: 289). Y es que política e ideología fueron dos de los parámetros que con mayor rapidez se afianzaron en el ámbito artísticocultural de la Europa de posguerra.

La segunda mitad de la década de 1920 trajo consigo un enérgico impulso a la historiografía picassiana de refrendo español. El artista malagueño comenzaba a erigirse en Europa y Estados Unidos como referente de un nuevo lenguaje plástico, lo que motivó algunos cambios en el tono de la historiografía de su país natal. Así, al fervor de la crítica más progresista se unió el interés de las esferas oficiales, que advirtieron la idoneidad del imaginario picassiano para el desarrollo de una nueva identidad nacional. De este modo, la revalorización del arte y la cultura como herramientas políticas y de propaganda explicaba, en buena medida, el interés creciente por la adhesión de Picasso a las filas de la plástica contemporánea española.

Algunos autores apuntan a la exposición de Picasso en la parisina Galería Georges Petit, en 1932 (Matsuda 2002: 620), como detonante de una nueva óptica de aproximación al artista que hizo especial hincapié en su dimensión humana, y que permitió al público trascender su producción plástica y cuestionar, así, aspectos que dependían no tanto del personaje como de la persona. Se trataba de una suerte de desarrollo orgánico inserto en el proceso de mitificación picassiano que llegó a su culminación en los años treinta: incuestionable ya su reputación como artista, parecía que solo quedaba determinar cuál sería su consideración en términos humanos. No en vano autores como Eunice Lipton han denominado al análisis del contexto crítico francés de aquella década The artist-hero arrives (Lipton 1976: 236-343). El estudio de Lipton cobra especial sentido al ponerse en sintonía con las investigaciones de Natalia Bravo Ruiz, dedicadas al ámbito español. A pesar de la diferencia geográfica, ambos coinciden en que dicho período marcó el inicio del fenómeno Picasso, entendido este como la legitimación definitiva del «genio» del artista. Bravo Ruiz (2003: 181-185) suma a esta cuestión connotaciones privativas de la historiografía española, derivadas del fervor nacionalista y de la incapacidad crítica en la defini-

* Este trabajo es resultado de una ayuda del Ministerio de Ciencia e Innovación (FPU19/03435) para realizar una tesis doctoral bajo la dirección de Miguel Cabañas Bravo e Isabel García García, y se inserta en el marco del Proyecto de Investigación I+D+i Rostros y rastros en las identidades del arte del franquismo y el exilio (MICINN, AEI, ref. PID2019-109271GB-I00). 
ción del conjunto de la producción pictórica picassiana, tendente a la compartimentación estanca de sus distintas etapas pictóricas.

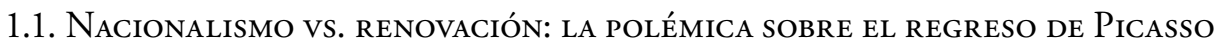 a España}

Al margen de la naturaleza política o cultural de los anhelos de recuperación del malagueño, la fiebre Picasso se hizo plenamente efectiva en Espańa a comienzos de la década de 1930. Hasta entonces, la etiqueta francesa que se había colgado al cuello del artista no pareció afectar las sensibilidades de la intelectualidad española. Es más, pocos fueron quienes realmente defendieron la genealogía del artista en pro de una crítica mayoritaria que veía en él al «verdugo de la pintura contemporánea» (Gómez de la Mata 1925: 23). De esta forma, los simpatizantes de Picasso reivindicaron la españolidad del artista y exigieron a la Administración la organización de una exposición antológica con la que dar a conocer su producción entre el público español. En palabras del crítico Sebastià Gasch (1930: 7), «España tiene una deuda de honor con Picasso. Confesémoslo con pena».

Así, la influencia creciente del artista a nivel mundial propició la movilización de un grupo de intelectuales vinculados a la revista Cosmópolis-entre ellos el duque de Alba, Mariano Benlliure, Juan de la Encina, José Francés, Eugenio D’Ors, Ortega y Gasset, Ramón Pérez de Ayala o el conde de Romanones- que, al estar próximo el cincuenta aniversario del artista, le instaron a regresar al país (Tusell 2017: 25-32). Rafael Marquina, director de la citada publicación, reafirmaba así su invitación: «Salvemos a Picasso de la triste fatalidad de ser consagrado en su patria después que para siempre haya cerrado los ojos» (Marquina 1930: 34). Resta decir que Picasso no acudió a la llamada, como tampoco lo hizo a la invitación oficial del Gobierno republicano tres ańos después, de cuya política expositiva se encargaba entonces Ricardo de Orueta, director general de Bellas Artes. Las gestiones, encargadas a Salvador de Madariaga, embajador de España en París, no dieron sus frutos y el Gobierno decretó definitivamente agotada su paciencia.

A tenor de lo expuesto se puede concluir que, en la breve horquilla de 1930 a 1933, los proyectos propuestos por la intelectualidad y la Administración española no hicieron otra cosa que deteriorar la ya exangüe relación entre Picasso y Espańa. Proyectos que contaron, además, con una gran oposición desde el interior. Así, personajes como Ernesto Giménez Caballero o Guillermo de Torre ponían el grito en el cielo ante la hipocresía de aquellos que reclamaban la propiedad del artista ${ }^{1}$. En este sentido, la defensa de Guillermo de Torre sí pareció encontrar un interés sincero en la recuperación artística española y, por ende, en la defensa a ultranza del arte nuevo. Tal circunstancia se vería ańos más tarde materializada en la articulación de la primera muestra antológica de Picasso en España, organizada por el grupo

\footnotetext{
1 Véanse Torre 1933: 230-240 y Giménez Caballero 1931: 1-2.
} 
de Amigos de las Artes Nuevas (ADLAN), y en la que el ultraísta jugó un importante papel. Semejante fue el caso de Eduardo Westerdahl, quien, años después, a propósito de la II Exposición Internacional del Surrealismo de Tenerife, recordaría la nefasta gestión de la República en su labor cultural, pues «algo notó (Picasso) en aquella invitación que defraudaba sus aspiraciones, o bien fuera la frialdad o falta de competencia de la crítica» (Westerdahl 1935: 1). No era la primera vez que el autor tinerfeño reivindicaba la necesidad de reconocer en Picasso al promotor de un nuevo lenguaje plástico. Para ello contó con la importante labor de difusión cultural de Gaceta de Arte de Tenerife. Considerada por la historiografía como baluarte de la renovación cultural en España, así como en el ámbito internacional, destacó, entre otras, por su «fe profunda y arraigada en las nuevas ideas estéticas como factor decisivo en el cambio social» (Castro Borrego 1978: 161).

\section{BALUARTES DE LA REGENERACIÓN CULTURAL EN ESPAÑA: CANARIAS Y LA DEFENSA DEL ARTE NUEVO}

Pese a la manifiesta miopía cultural que los sucesivos gobiernos españoles de las primeras décadas del siglo xx mostraron hacia la renovación artística del país, existieron iniciativas privadas que allanaron el terreno y participaron activamente del despegue cultural de la década de 1930. Desde Revista de Occidente a Diablo Mundo, de Corpus Barga, pasando por La Gaceta Literaria, Octubre, AC o Arte, órgano de difusión de la SAI (Sociedad de Artistas Ibéricos) -promotora de numerosas exposiciones de arte contemporáneo español, tanto dentro como fuera de sus fronteras-, los esfuerzos de un reducido sector, vinculado generalmente a las dos capitales artísticas del momento -Madrid y Barcelona-, fueron decisivos en la lucha por la regeneración cultural del país (Bonet 1997: 259-265). En febrero de 1932 Tenerife se sumaba a la revolución con la publicación del primer número de Gaceta de Arte (GA), al resituar al archipiélago en la escena artística desarrollada tanto en la península como en el contexto internacional. Fruto de una visión abierta e imparcial, la publicación se caracterizó por su arriesgada apuesta y defensa de lo autóctono, y demostró su capacidad de simbiosis con las propuestas internacionales más transgresoras: «gaceta de arte [...] cumplirá en la isla, en la nación, en europa [sic.], la hora universal de la cultura» (Gaceta de Arte 1932: 1).

\subsection{Picasso visto desde Canarias: lecturas de Gaceta de ARTE}

Una de las novedades planteadas por $G A$ fue su extensa profundización teórica en la producción de artistas vinculados a la plástica internacional, tales como George Grosz, Paul Klee, Constantin Brancusi, Hans Arp, Wassily Kandinsky o Pablo Picasso. En este sentido, la publicación isleña fue sujeto de una significativa aportación conceptual a la crítica picassiana, que superó la atávica metodología formalista, aunque mantuvo la idea romántica del genio, patente en la defensa del antiintelectualismo e individualismo presentes en el proceso creativo del artista (Bravo 
Ruiz 2003: 202-208). Al analizar el contenido de los treinta y ocho ejemplares que conforman la revista, salpicados todos ellos por citas a Picasso de extensión variable, se han determinado diferentes procedimientos de aproximación metodológica a su obra: por un lado, desde la reivindicación y la defensa tanto de su ideario como de su producción, especialmente evidente en los dos monográficos del $\operatorname{artista}^{2}$; por otro lado, desde la óptica del prisma surrealista, presente en múltiples exégesis de su obra, así como en las connotaciones implícitas en las imágenes que acompañan algunos de los textos ${ }^{3}$.

En agosto de 1932, GA dedicaba su séptimo número a Picasso con motivo de la retrospectiva anteriormente citada en la Galería Georges Petit, a la sazón espacio expositivo por antonomasia del grupo surrealista parisino. Asimismo, la fecha de publicación coincidía con la también mencionada polémica en torno al retorno del artista a España, liquidada con el desengaño del Gobierno ante las repetidas negativas del malagueño. En palabras de Oscar Pestana (1932: 1): «El recuerdo que (Picasso) guarda de España es un toro sucio que lo cornea en las noches de pesadilla». Un recuerdo que culminó con la consabida celebración de la exitosa Segunda Exposición Internacional del Surrealismo de 1935, cuya instrumentalización sirvió para que el grupo tinerfeńo recriminara la negligencia gubernamental. De vuelta al verano de 1932, fueron Óscar Pestana, Domingo López Torres, André Salmon o Henri Mahaut algunos de los nombres que participaron en el primer monográfico que el país dedicaba al malagueño. Así, aquel homenaje en papel sirvió como piedra de toque para las nuevas dinámicas interpretativas de la obra de Picasso, hasta entonces entendida como contradictoria y, en consecuencia, errática, y analizada en base a períodos estancos que eludían el organicismo y continuidad inherentes a su producción. Eduardo Westerdahl fue uno de los críticos españoles que con mayor profusión abrazaron la tan picassiana convivencia de opuestos:

En toda su obra no se aparta de este andar y estarse quieto, de lo apacible a lo monstruoso, de lo que forma a lo que deforma. / época azul y rosa -apacible (cualidad promedio) / época negra -trágica/ $1 .^{a}$ época cubista -apacible / $2 .^{a}$ época cubista -trágica / época de recién casado - apacible / Hasta llegar al periodo greco-romano, tendencia, como en las anteriores en que abre sus caminos de lo sereno a lo dramático (Westerdahl 1932: 2).

2 Junto con los dos monográficos, a través de la sección titulada «Actividades del espíritu", dedicada generalmente a la crítica literaria, se atacó a personajes como Giménez Caballero, a quien se acusó de falangista, o a Manuel Abril por su falta de rigor al analizar la obra picassiana en De la naturaleza al espiritu (1935). Otros de los blancos de GA fueron Eugenio D'Ors o Carlo Belli.

${ }^{3}$ Otro de los arquetipos picassianos aplicable también a la retórica surrealista se observa en las imágenes empleadas en la ilustración de la revista. Las obras que $G A$ reproduce del malagueño pertenecen a un período similar al que había sido estandarte del cubo-surrealismo auspiciado por el grupo de París, desde las bañistas de 1920 -figuras orgánicas y metamórficas que recuerdan a la producción de artistas como Masson, Ernst o Dalí- a creaciones de la década de los treinta, tales como la Muerte de Marat (1934) -que no solo ilustró dos números de GA, sino también el Segundo Boletín Internacional del Surrealismo, publicado en 1935- o La crucifixión (de Grünewald) (1935). 
La defensa del universalismo y la razón de $G A$, sumada al candente debate en torno a la función social del arte y del artista, encontraron su correlato en la figura del malagueño: «El cubismo es el patrón por el que la nueva generación aprenderá a ver el mundo de una manera racional» (López Torres 1932: 1). Cuatro ańos después, en un extenso ejemplar que cubría los meses de marzo, abril y mayo de 1936, y ante la imposibilidad de que la muestra antológica Picasso, de ADLAN, viajara a las islas, $G A$ dedicó su segundo monográfico al artista. Dicho ejemplar se nutría de una variada nómina de críticos y artistas del ámbito nacional e internacional, y de él se desprende un discurso estético que bebe inequívocamente de los postulados surrealistas. Asimismo, se publicaron dos poemas inéditos del malagueño, acompañados por un ensayo de André Breton ${ }^{4}$. No pudo faltar el comentario de Paul Éluard, como tampoco el texto que, en términos nacionales, firmaba Ramón Gómez de la Serna (1936: 21): «Hay que conocer España para saber de qué fondo abrupto, blasfemo y rebelde brota Picasso». Y es que $G A$ no fue ajena a la reivindicación del españolismo picassiano: «Picasso es tan ajeno a Francia como todo lo que es espańol. Y nada ni nadie es tan español como Picasso" (Pérez Alfonseca 1934: 4).

Concluía el número treinta y siete con la «Apología del cubismo» de Guillermo de Torre, autor de una sucinta bibliografía que acompañaba el catálogo de la muestra, y que fue incluida en aquel ejemplar junto al manifiesto de ADLAN. En este sentido, no es en absoluto baladí que su opúsculo fuera ilustrado con obras como el Guillaume Apollinaire picassiano, así como alguna otra de Juan Gris y Braque, compañeros del malagueño en la aventura cubista, «una estética que proponía un nuevo medio de mirar, de conocer el mundo sensible» (Torre 1936: 36). Algo reseñable es la experiencia cuasi mística con que De Torre definía en su texto la retórica cubista, a través de un relato cronológico marcado por las conexiones entre el movimiento y las dialécticas platónica y socrática, pasando por Kant y la escolástica de los siglos XVI y XVII, hasta llegar a Maurice Raynal y Blaise Cendrars, para concluir con Méditations esthétiques, de Apollinaire. Con todo, parece que fue la idiosincrasia bretoniana la que caracterizó la exposición de los Amics de l'Art Nou: lo que prometía ser una antología de la obra picassiana se redujo a un período concreto de su trayectoria. Tal y como recoge un artículo de la revista Re-co, órgano del Centro de la Construcción, y a su vez espacio que acogió la muestra en Madrid, «en la exposición actual están representadas las maneras capitales de Picasso, el cubismo, la época de las abstracciones y metamorfosis, y su modalidad última» (Domènech 2011: 191). En este sentido, $G A$ contribuyó ampliamente al impulso de las dinámicas surrealistas en España, participó en los debates de la crítica internacional y favoreció la difusión de las formas de pensamiento del grupo de Breton y sus acólitos.

${ }^{4}$ Bajo el título 28 de noviembre XXXV y 24 de diciembre XXXV, las imágenes propuestas en las composiciones poéticas del malagueño, escritas en 1935, se resuelven hijas legítimas de la retórica surrealista, tal y como corrobora la firma bretoniana en su ensayo introductorio. Véase (1936): «Poemas inéditos de Picasso», Gaceta de Arte 37: 18-19. 
En base a lo expuesto, una de las hipótesis que aquí se plantean parte de las concomitancias advertidas entre la reivindicación picassiana manifiesta en las páginas de $G A$ y el empeño que el grupo surrealista parisino venía realizando, en una línea similar, desde mediados de los años veinte. Esta circunstancia podría, además, ser considerada entre las múltiples motivaciones que justifican la participación de Picasso en la muestra surrealista tinerfeña de 1935, así como la amplia presencia de Breton en la exposición organizada por ADLAN un año después. Tal afirmación toma como punto de partida el mes de julio de 1925, momento en que Breton publicaba su famoso manifiesto "Le surréalisme et la peinture», en el número 4 de La Révolution Surréaliste. La digresión del francés legitimaba de manera decisiva la inserción de Picasso en las filas del surrealismo, con lo que restaba importancia a la, aparentemente limitada, vinculación del malagueño con los procesos creativos inherentes al movimiento: «Le surréalisme, s'il tient à s'assigner une ligne morale de conduite, n’a qu'è en passer par où Picasso en a passé et en passera encore» (Breton 1925: 30).

La tesis de Breton, no exenta de numerosos detractores 5 , partía de la reivindicación picassiana, no tanto desde una perspectiva estético-formal como desde un plano moral. Esto último resulta especialmente interesante al confrontarse con un texto de Westerdahl para el vigésimo quinto número de $G A$, titulado "Croquis conciliador del arte puro y social». Para el crítico canario, el surrealismo -en el que no dudaba en insertar a Picasso- «se pone al servicio de una revolución espiritual» (Westerdahl 1934: 2). De este modo, la significación que $G A$ concedió a la cuestión moral y espiritual de la plástica surrealista mantuvo a Picasso como efigie. Arte puro y arte social se alzaban como un binomio llamado a convivir en armonía dentro de la plástica surrealista. Diez números más tarde, la revista tinerfeña insistía en este planteamiento al hacerse eco de una crítica dedicada por la francesa Cahiers d'Art:

Entre los principales grupos que merecen nuestra más decidida atención, figura el movimiento surrealista, en quien desde el principio vimos uno de los más interesantes instrumentos de que dispone una cultura viva para abrirse paso en medio de las amenazas constantes que sufría la independencia del espíritu y de las coacciones y falsas obras de ingeniería con que el capital, el estado, la religión, la moral, la patria, la familia, etc., canalizaban y levantaban convencionales edificios al servicio de sus unilaterales intereses, con preciosos materiales subconscientes en cuya energía descansaba el proceso de las culturas. A g.a. le une al surrealismo en principio su fondo anticapitalista y universal, la destrucción de la sociedad burguesa y las escenográficas instituciones que maltratan y aniquilan el libre acto (Gaceta de Arte 1935: s/p).

5 A este respecto, el análisis propuesto por Rocío Robles, al igual que Rafael Jackson, apunta también a la cuestión de la apropiación picassiana por parte del surrealismo moral y político de Breton, al tiempo que manifiesta la opinión contraria de los múltiples críticos y personajes del mundo del arte que se opusieron al juicio bretoniano, tales como Brassaï, Jean Clair o Michael Leiris. 
A ello debe añadirse la influencia del llamamiento a la movilización política en términos revolucionarios formulado por Breton en su Seconde manifeste (1929), seguido del cese de la revista La Révolution Surrealiste, que fue sustituida por Le Surréalisme au Service de la Révolution (1930-1933), cuyo director fue el mismo Breton, y entre cuyos colaboradores destacaron Paul Éluard, Louis Aragon, Luis Buñuel, Salvador Dalí, Max Ernst, Paul Nougé, Benjamin Péret o Yves Tanguy (Mañero 2013: 213). Este planteamiento sería legitimado por el grupo canario, tal y como se desprende de las firmas que suscribieron el Segundo Boletín Internacional del Surrealismo, publicado en octubre de 1935, en lo que resultó una férrea declaración de principios en defensa del ser colectivo y social: «El "ello" -lo ancestral y colectivo-se coloca en franca lucha con el "yo" - lo consciente y personal-» (Breton et al. 1935: 1-2). De este modo, la muestra de 1935 selló definitivamente el pacto de $G A$ con la causa revolucionaria del surrealismo internacional. Pese a ello, no deben olvidarse las especificidades del caso español y la repercusión que en tal compromiso tuvo el contexto cultural del primer tercio del siglo xx. A propósito de lo cual resulta oportuno recuperar aquí un texto del poeta canario Agustín Espinosa, publicado en $G A$ bajo el título "Ars Republicae», una crítica al profundo desencanto ante un Gobierno en el que, tras el Directorio militar de Primo de Rivera, la intelectualidad española había puesto sus esperanzas:

Muchas veces da más aliento a una causa la altura de sus signos plásticos, el juego de arte en que ella se vuelca, que la ética de su doctrina o el primor de sus paladines o el candor mismo de sus mejores gestos, navega el barco a toda vela entre vientos (Espinosa 1933c: 4).

Con la revulsiva retórica que caracteriza su producción literaria, Espinosa arremetía contra los símbolos de un sistema cultural que consideraba caduco, en lo que se traduce en una defensa al valor del arte como garante del progreso social.

\section{ESPINOSA "EN SU ELEMENTO": VANGUARDIA, CUBISMO Y RENOVACIÓN CULTURAL EN LAS ISLAS CANARIAS}

Tal y como se viene apuntando, $G A$ había nacido con ánimo de reubicar al contexto insular en el eje de los circuitos de la vanguardia europea. En este sentido, la elección del Ateneo de Tenerife como una de las sedes que acogieron la Segunda Exposición Internacional del Surrealismo -la muestra había pasado por Copenhague, y más tarde viajaría a Londres- supuso la cristalización de la idiosincrasia canaria, al tiempo que el reconocimiento de la isla como capital ecuménica de la cultura. Uno de los agentes protagonistas de aquella empresa fue el poeta Agustín Espinosa, quien por entonces ostentaba el cargo de presidente del Ateneo, firmante, asimismo, del Segundo Boletín Internacional del Surrealismo. Fue, además, el encargado de presentar la famosa conferencia ofrecida por Breton en el Círculo de Amistad XIV de Abril. Junto con su participación activa en la organización de la muestra y sus actividades anejas, colaboró ampliamente a través de una notable labor de difu- 
sión en medios canarios como La Tarde o La Prensa. Fue precisamente en La Tarde donde Espinosa escribió un texto rebosante de entusiasmo, titulado «Navidades de primavera. Breton, Péret y Éluard, nuevos Reyes Magos, en Canarias», publicado el 4 de mayo de 1935. El testimonio de Espinosa trae a la memoria el retorno a la infancia propuesto por Breton al referirse a las obras de Picasso, a las que consideraba «juguetes trágicos para adultos» (Breton 1925: 30):

Esto puede hacer el milagro de que Tenerife vaya a tener sus Reyes Magos en primavera y su Navidad en área de mayo. Esto puede hacer también que se hagan niños, en esta cálida Natividad inesperada, todos los sońadores de Canarias, y que devengan sus ojos zapatos de noche de reyes y tenga su despertar campanas de excepcionales albas (Espinosa 1935: 215).

Con todo, la labor desempeñada por el canario no se limitó a la exposición surrealista, ni tampoco a la época de $G A$. Lo cierto es que, desde finales de la década de 1910, el contexto insular había sido testigo de una eclosión de publicaciones de vocación vanguardista. Una de aquellas manifestaciones, de las que destaca su empeño en el enriquecimiento cultural canario, fue La Rosa de los Vientos (1927-1928), que contó con Agustín Espinosa como jefe de redacción. No es extraño que, tras su regreso a Canarias en 1924, el poeta comenzara a aplicar la experiencia cosechada tras su estancia en Madrid, ciudad en la que recaló el mes de junio de 1919, y en la que tuvo acceso a los círculos vanguardistas más transgresores (Pérez Corrales 2019: 308).

\subsection{Actores y Dispositivos DE LA RENOVACIÓN CUltural CANARIA: EsPinOSA Y} LA ROSA DE LOS VIENTOS

Algunos autores han apuntado al advenimiento de un «renacimiento cultural canario» en lo que compete a la producción cultural insular del primer tercio del siglo xx (Rodríguez Doreste 1965: 50). Fue entonces cuando se comenzaron a rastrear nuevas publicaciones, postulantes de dinámicas ajenas al academicismo de la España del momento, tales como Castalia (1917), La Rosa de los Vientos (19271928) o Cartones (1930). Si bien es cierto que estas hubieron de convivir con otros títulos de un todavía excesivo pintoresquismo, su empeño por reforzar la imagen cultural canaria es digno de alabanza, «un ambiente como era este de Santa Cruz -de Tenerife, de Canarias- tan poco propicio y tan desmańadamente cultivado en cuanto se refiere a manifestaciones de arte y de cultura» (Hespérides 1928: 7). La exigencia en analizar tales precedentes, entre los que destacó sobremanera $L a$ Rosa de los Vientos $(L R D L V)$, resulta necesaria debido a tres cuestiones: en primer lugar, por su estrecha vinculación con Agustín Espinosa; en segundo lugar, por ser los principios de $L R D L V$ correlato del mensaje del que, unos años después, $G A$ se hizo eco; por último, porque en ella se han podido rastrear las primeras críticas de impronta canaria que se dedicaron al cubismo y a Picasso.

La nómina de colaboradores que participaron en los cinco números que conforman $L R D L V$ guardaba estrecha conexión con los círculos con que Espinosa 
se relacionó durante su estancia en la capital española. Uno de aquellos nombres fue Ramón Gómez de la Serna, a quien el poeta debió conocer a comienzos de los años veinte, y cuya intervención en $L R D L V$ llegó a convertirse en costumbre (Bonet 1997: 259-265). A su vez, el formato y tono literario de la publicación canaria sugiere una metodología similar a la empleada en La Gaceta Literaria (1927-1932), revista cultural editada en Madrid y dirigida por Ernesto Giménez Caballero, en la que Espinosa publicó algunos textos ${ }^{6}$. Asiduos a aquel medio fueron también otros personajes como el ultraísta Guillermo de Torre, el ya citado Ramón Gómez de la Serna, el crítico Manuel Abril, E. Tériade', Eugenio D’Ors, Jean Cassou o Eduardo Westerdahl. Tal coyuntura permite explicar la influencia de los ismos -desde el ultraísmo y el simultaneísmo al futurismo o el cubismo- tanto en la estética como en el contenido de $L R D L V$. Contenido que, por otro lado, serviría de cimiento para la construcción posterior del discurso de $G A^{8}$.

La apuesta de $L R D L V$ por la defensa de las últimas tendencias artísticas internacionales se materializó también en artículos como «El ángulo recto en el cubismo", de Rodríguez Doreste, o en semblanzas como la dedicada a Juan Gris por Ernesto Pestana. Al igual que en La Gaceta Literaria, las alusiones a Picasso fueron frecuentes; y es que, como afirmaba Pestana: «Para hablar del cubismo de Juan Gris es necesario hablar del cubismo de Picasso» (Pestana 1927: 15). De hecho, al analizar la publicación madrileña es posible determinar que la presencia del malagueño entre 1927 y 1928 -los mismos ańos de andadura de $L R D L V$ - fue una constante (Gómez y García 2009: 30-33). Giménez Caballero lo reflejaría así en una de las muchas reivindicaciones que hizo de su figura, una defensa que también ocupó algunas de las reflexiones de Espinosa:

Nos llaman vanguardistas porque defendemos una cosa tan multisecular como el cubismo [...] Nuestras campañas son un asunto de calidad, venga de donde venga, venga de derecha, venga de izquierda. Picasso no es bueno porque pinte «moderno». Aún cuando pinte «moderno» Picabia será siempre «malo» (Giménez Caballero 1928: 2).

${ }^{6}$ Una de las primeras y más relevantes obras de Espinosa, Lancelot, $28^{\circ}-7^{\circ}$, fue precisamente publicada en La Gaceta Literaria el 15 de marzo de 1929.

${ }^{7}$ E. Tériade había sido, junto con Albert Skira, uno de los fundadores de la publicación surrealista parisina Minotaure (1933-1939), cuyo primer número contó con la participación de Breton, quien escribió el famoso opúsculo «Picasso dans son élément», acompañado de fotografías de Brassaï.

${ }^{8}$ Las similitudes ideológicas que se desprenden de $L R D V$ y $G A$ demuestran la continuidad entre esta y el discurso de su antecesora. En este sentido, el 1 de febrero de 1928 se publicaba en $L a$ Prensa el primer manifiesto de $L R D L V$, inaugurado mediante las siguientes palabras: «Por siempre: Universalismo sobre Regionalismo». La vocación internacionalista que de ellas se desprende ha de sumarse al sentido social y la idea de cambio que la misma «Rosa de los Vientos» lleva implícito: se trata del símbolo de las nuevas coordenadas que perseguía el grupo. Tales propósitos fueron posteriormente recuperados por $G A$. 


\subsection{Reflexiones SObRe El CUBismo EN LA ObRA DE ESPINOSA}

Sea como fuere, la presencia del cubismo en $L R D L V$ no era una circunstancia fortuita, como tampoco lo había sido el contacto de Espinosa con los núcleos de vanguardia que más ampliamente difundieron el movimiento en Espańa. Si su paso por Madrid había resultado fructífero, más aún lo sería su viaje a París a principios de 1930, pensionado por la JAE (Pérez Corrales 2019: 308). Lo aprendido en la capital francesa se concretaba en el fortalecimiento de su visión anticapitalista, así como en una mayor y más sólida conciencia política, acaso potenciada por la influencia de la retórica surrealista. Una retórica que desde 1925 defendía con voraz apetito la anexión de Picasso. A propósito del malagueño, fue precisamente en 1930 cuando la revista surrealista Documents -surgida de la escisión del grupo surrealista tras la expulsión a la que Breton condenó a algunos de sus integrantes primigenios- dedicaba un número al artista, y en el que Georges Bataille catalogaba su obra como suprarrealista, en oposición al discurso defendido por Breton (Jackson 2003: 88). Esta coyuntura pudo influir a Espinosa, en cuya obra literaria se observan elementos característicos de la estética cubista, así como algunas notas que se sumaban a la reivindicación historiográfica de Picasso.

\subsubsection{De Horta de Ebro a las Islas Canarias: la geometrización de Lancelot, $28^{\circ}-7^{\circ}$}

No hay duda de que Espinosa conocía al artista malagueńo, pese a que no sea posible asegurar con certeza que ambos coincidieran personalmente ${ }^{9}$. Una de las evidencias más notables de este hecho yace en el estilo literario empleado en una de sus primeras obras, Lancelot, $28^{\circ}-7^{\circ}$, publicada en 1929 . El texto de Espinosa se sirve de recursos propios del lenguaje cubista, una fórmula sin precedentes en la literatura española. La geometrización se aplica rigurosamente en la descripción del paisaje de Nazaret, «un pueblo de paralelepípedos blancos» (Espinosa 1929: 31), trasunto de la geografía canaria y recuerdo, además, de la minuciosidad matemática de la bíblica Jerusalén Celeste. Al mismo tiempo, la visualidad de las imágenes literarias remite a las obras realizadas por Picasso durante su segunda estancia en Horta de Ebro, en el verano de 1909, a las que la historiografía general atribuye el germen de la hazaña cubista: «Horta significó para Picasso y el cubismo, la cristalización de éste en la forma que se ha venido a denominar geométrica» (Francin 1981: 33). Una trasposición plástica que recuerda, asimismo, a la temática predilecta de la experimentación estética del cubismo: los paisajes de Cézanne y las naturalezas muertas de Braque y Picasso.

9 Una noticia del 5 de julio de 1917, en la página 2 del Heraldo de Madrid, se hacía eco del banquete que Ramón Gómez de la Serna organizó a Picasso en la madrileña Sagrada Cripta de Pombo con motivo del estreno del ballet Parade, para el que el artista había confeccionado decorados y vestuario. Entre los asistentes a la cena que cita el diario en cuestión se incluye el nombre de «Espinosa». Si bien es cierto que el poeta no se instalaría definitivamente en Madrid hasta 1920, encontrándose entonces en Granada, cabe la posibilidad de que, efectivamente, hubiera acudido a la capital para el visionado de la pieza y, por ende, coincidiera con el malagueño. 
El oriente más fino, más auténtico, de los verdaderos orientes, ha construido este paisaje silencioso, hermético, frío. Hecho de bruñidas masas rectangulares [...].

El paisaje de Nazaret expone perennemente su gran geometría de horizontales. $\mathrm{Ni}$ el árbol -bajísimo, enano, como chafado por el propagandista de lo horizontalrompe aquí el equilibrado horizontalismo. (Frente al chopo de Castilla -erguido, vertical- se acuesta la higuera horizontal de Ye).

Hasta unas nubes bajas que la tarde ha traído sobre Nazaret han ido buscando el paralelismo de sus aéreos prismas imperfectos del cielo con los paralelepípedos perfectos de la tierra. Las casas de Nazaret piensan entonces que se están mirando en el espejo (Espinosa 1929: 32).

El factor geográfico, frecuente en la literatura y plástica insulares, encandiló a muchos autores de la vanguardia internacional, incluyendo al mismo Breton, y como refleja El castillo estrellado - publicado en la bonaerense revista Sur en abril de 1936-, texto en el que el francés elogiaba el esplendor del Teide. Un elogio similar al que Picasso hizo a la montaña de Santa Bárbara en sus óleos de Horta, y que Espinosa aplicó en la composición de Nazaret. Emeterio Gutiérrez Albelo, cuya crítica fue contemporánea a la publicación de Lancelot, fue uno de los primeros autores en establecer paralelismos entre la obra de Espinosa y la plástica de su tiempo. Tomaba, así, una cita de Leonce Rosenberg -encargado de la organización de la gran retrospectiva de Picasso en la Georges Petit en 1932- donde el que fuera marchante del malagueño afirmaba que «el arte tiene por fin no reconstruir un aspecto de la Naturaleza, sino construir equivalentes plásticos, y el hecho de arte así constituido deviene un aspecto creado por el espíritu» (Gutiérrez Albelo 1929: 296). Clausuraba Albelo su crítica analizando el camino seguido por Lancelot, que había sido capaz de sustituir «el objeto por su esquema. El sujeto, por su esencia» (ibid.: 297).

La esquematización sintética de las formas, así como la búsqueda de la esencia y la pureza del objeto, no era máxima exclusiva de la retórica suprarrealista del movimiento. De hecho, uno de los grandes episodios de la Generación del 27 fue la reivindicación de Luis de Góngora, en cuya obra encontraban el legítimo precedente del cubismo (Palenzuela 1991: 24-31). Tenerife se sumó rápidamente a aquella demanda, y Espinosa dedicó una antología del poeta barroco que cubrió las páginas del segundo número de $L R D L V$, el mismo que acogía la oda al ángulo recto de Rodríguez Doreste. Las estrofas del soneto gongorino «De pura honestidad templo sagrado» fueron rebautizadas por Espinosa como "La dama cubista». Nilo Palenzuela, quien ha analizado en profundidad dicha lectura en clave geométrica, considera este comportamiento «una apropiación cubista de la obra y la figura gongorinas» (Palenzuela 1991: 26). Esta curiosa resignificación sería repetida dos décadas después por el propio Picasso, quien, como Espinosa, también dedicó su homenaje personal al poeta barroco ${ }^{10}$. Volviendo a la antología de Espinosa, el canario acom-

${ }^{10}$ Entre 1947 y 1948 Picasso transcribió una serie de sonetos, entre ellos los recogidos por Espinosa en su antología, que acompańó de diversas ilustraciones. Los sonetos tomados por Picasso en su relectura procedían de una edición francesa hecha en 1928 por el hispanista Zdislas Milner, 
pañó su pequeño elogio con «De Don Luis de Góngora, en el retorno de su hora poética", cuyo lenguaje puede considerarse precedente de la posterior descripción geométrica de Nazaret:

Geometría y módulos. El Guadalquivir.- Junto a la geometría laberíntica de la mezquita está el coro barroco. El Guadalquivir atisba, tras el florido naranjal fronterizo, la severa silueta morisca del coliseo. Góngora ha paseado bajo las uniformes arcadas. Allí está la geometría resuelta en orientales orfebrerismos. Allí está la curva y la recta. Lo metafórico geométrico se ha hecho plástico. Ha parido formas vivas. [...] Y cambia, ahora, Góngora el bosque cubista por la selva virgen. La selva virgen del coro inicia el otro tema. El tema bíblico germinador. Para Góngora sólo existe el módulo. Sus ojos helenizan bellamente los motivos: Jesús es Polifemo; Sinaí, Olimpos; María, Galatea. Pero el equilibrio de la forma flotaba bajo las flautas polítonas de los angelitos-efebos del órgano (Espinosa 1927: 11).

\subsubsection{Espinosa en la década de 1930: recuerdo y vindicación del cubismo y de Picasso}

La estética cubista que caracterizó Lancelot, $28^{\circ}-7^{\circ}$, en torno a la cual pivotaron también algunos de los escritos de finales de 1920, fue levemente desplazada de la producción de Espinosa iniciada la década siguiente. En su lugar, los escritos del poeta canario adquirieron un tono comprometido con la defensa del arte de vanguardia, a cuyo frente situó a Picasso y Nonell, emblemas de la generación pictórica más joven ${ }^{11}$. Así, el lenguaje y la estética cubistas se concretaron en textos como "Elogio a la Burbuja», a propósito de la última obra poética de Manuel Verdugo, Burbujas. Publicado en abril de 1931, el elogio de Espinosa recurre a la temporalidad dual del cubismo, espejo de la tradición y arquetipo del cosmopolitismo moderno. El autor contrapone críticamente estos valores a Burbujas, los cuales sugieren también una mordaz respuesta a un texto publicado por Verdugo en la revista Horizontes, el 23 de mayo de 1927 en La Laguna, donde arremetía «[...] contra los escritores "cubistas", a los que llama animales y considera ininteligibles, para acabar con una divertida fórmula de vanguardias ("Suprarrealismo $\times$ Futurismo / Cubismo = Carcajada”)» (Pérez Corrales 2019: 312).

En «Cocteau en España. Diario de una europeización», publicado en $L a$ Prensa el 1 de octubre de 1931, Espinosa ponía especial atención a Le coq et l’Arlequin, pieza aforística del poeta francés, traducida al castellano por José Bergamín en 1923, en la que Cocteau defendía la experimentación musical del compositor Erik Satie,

editada por Cahiers d'Art y acompañada de ilustraciones de Ismael González de la Serna, artista de veta cubista. La obra se titula XX sonnets y se conserva actualmente en la Biblioteca Nacional. Véase Trueblood 1989.

${ }^{11}$ Tal consideración fue apuntada por Espinosa en su obra Oda a María Ana, primer premio de axilas sin depilar de 1930. Recogido de J.M. Pérez Corrales (ed.) (2017): Agustín Espinosa. Oda a Maria Ana, primer premio de axilas sin depilar de 1930. Textos 1930-1931, Tenerife: Ediciones Insoladas, 157. 
a propósito de los ballets rusos de Diaghilev. Este hecho resulta especialmente revelador al incluir el citado manual un gallo y un arlequín -imagen predilecta en el corolario iconográfico cubo-surrealista-, así como un retrato de Cocteau, todos ellos de factura picassiana; más aún si se tiene en cuenta que había sido el francés quien había invitado a Picasso a participar en el diseño del vestuario y decorados de uno de los citados ballets: Parade. De esta suerte, las referencias a Parade refuerzan las conexiones Picasso-Espinosa. Este idilio continuaba en Media hora jugando a los dados, edición de una conferencia en torno al pintor canario Jorge Oramas, leída por Espinosa el 20 de abril de 1933 en el Círculo Mercantil de Las Palmas de Gran Canaria:

Hay en la última pintura del mundo una estimación por el dado. Es una especie de naturaleza muerta que enerva, sobre todo, a los pintores cubistas. Flotan los enlunarados cubos en los lienzos de Pablo Picasso, de Juan Gris y - ¿por qué no?de José Jorge Oramas [...]. Yo mismo, he hecho jugar a mi Lancelot a los dados, movido por el fatal signo del siglo, y he visto una influencia dadil en la arquitectura de Nazaret y Mozaga (Espinosa 1933a: 24).

El simbolismo inherente a la significación del dado bebe de la tradición mallarmiana, y remite a ciertas composiciones picassianas en las que dicho elemento deviene ingrediente principal. Tal es el caso de La Crucifixión (1930, MPP), en la que un agonizante Mesías asiste al juego de dados con que los soldados se disputan sus vestiduras. El carácter simbólico de la exégesis de Espinosa está presente en la evocación picassiana, donde mito, sacralidad y realidad juegan un papel clave en la composición. La transcendencia de esta metáfora fue apuntada por José Mateo Díaz, quien juzgaba la prosa de Espinosa como «una prosa mágica, rica en sugestiones y sugerencias [...] que se aglomeran y yuxtaponen como los planos de un cuadro cubista» (Mateo Díaz 1933: 260). En una línea similar se encuadraba «Toque de diana. Felo Monzón, a $90^{\circ}$ latitud norte», texto publicado por el Diario de Las Palmas el 2 de junio de 1933, de nuevo, una reivindicación de la corriente cubista canaria personificada en el pintor Felo Monzón, cuya estética organicista evoca la producción de Yves Tanguy o André Masson. Espinosa aludía con amargura a la indiferencia cultural hacia el artista:

Felo Monzón -el honesto, el pulcro, el candoroso Felo Monzón- es olvidado, en tanto. Pero ¿no es este el triste caso tradicional de que nuestra historia está llena de ejemplos, desde Peral hasta Picasso, pasando por Ramón y Cajal, y por Falla, y por Albéniz y por tantos y tantos? (Espinosa 1933b: 230).

Su protesta se ampliaba, además, a la reivindicación de Picasso en un momento en que la recuperación oficial del malagueño ocupaba buena parte de los titulares de los diarios nacionales. Un año antes, coincidiendo con el inicio de las colaboraciones de Espinosa en $G A$, algunos diarios se hacían eco de la lucha de la revista en aras de tal empresa:

«Gaceta de Arte» -dice una hojilla intercalada- apoya la campańa iniciada en los centros intelectuales de la República española, por sectores de juventud, a fin de 
que la figura Picasso tome el digno perfil en el mapa artístico nacional. España, patria del pintor y república joven, no puede menos de oponer a toda la labor del arte último, académico, monarquizante, -localista, ramplón, ridículo-, la figura de uno de los grandes hombres universales contemporáneos: Pablo Ruiz Picasso (La Prensa 1932: 2).

\section{REPENSANDO A ESPINOSA: CONSIDERACIONES FINALES}

La cita anterior, publicada en La Prensa el 18 de septiembre de 1932, resume a la perfección el triple compromiso adquirido por la crítica artística de los años treinta al que aludía M. ${ }^{a}$ Isabel Cabrera, apuntado al principio de este estudio, al tiempo que demuestra la idoneidad de la efigie picassiana como herramienta por excelencia para su consecución. La regeneración cultural del país debía comenzar por el reconocimiento de uno de los pilares sobre los que se había asentado el nuevo lenguaje de la vanguardia internacional: el malagueño Pablo Ruiz Picasso. El motivo de la elección de Picasso radicaba en sus raíces hispanas, a partir de las cuales era posible reclamar y legitimar la posición que la crítica española exigía para la producción artística nacional. La amplia presencia del artista a lo largo de las páginas de $G A$ permite situar a la revista y al grupo tinerfeño entre los principales agentes de reivindicación picassiana en el país en la década de 1930. Pese a la existencia previa de una línea de acción en este proceso de regeneración cultural a través del andaluz, $G A$ fue capaz de sistematizar aquellos anhelos mediante la consolidación de una nueva concepción estética de la obra de Picasso. Asimismo, aunque con alguna excepción, la mayor parte de autores que favorecieron el proyecto de $G A$ huyeron de la instrumentalización de Picasso como agente integrador del país, esto es, evitaron el acercamiento al artista en clave nacional, a diferencia, por ejemplo, de las dinámicas seguidas por Cosmópolis y por la propia Administración republicana.

La defensa de la proteica estética picassiana se unió a la polémica en torno al compromiso social del arte, un debate en el que el artista también actuaba como pieza central. Las propuestas defendidas por $G A$ en esta línea bebían de forma inequívoca de la retórica revolucionaria bretoniana. No debe olvidarse que había sido Breton quien, ańos antes, instalaba a Picasso en primera línea de guerra del surrealismo comprometido y militante. Esta adhesión a la doctrina del crítico francés resulta lógica si se atiende a la vocación universalista del grupo canario, así como a diferentes acontecimientos que acentúan su filiación surrealista. Destacan especialmente dos: la recepción de la Segunda Exposición Internacional del Surrealismo en el Ateneo de Tenerife y la publicación del Segundo Boletín Internacional del Surrealismo por los miembros de $G A$. Con todo, sería inadecuado omitir las especificidades del caso español. En primer lugar, porque existieron múltiples discrepancias entre el grupo francés y algunos surrealistas tinerfeños, quienes rechazaban las exigencias formales impuestas por la ortodoxia marxista (Aznar Soler 2010: 361). En segundo término, porque España no había sido ajena a los discursos plásticos que resonaron con fuerza en los treinta, y mucho menos en el ámbito canario. Es esta circunstancia, sumada 
al alcance internacional de $G A$, la que ha llevado a teorizar en torno a la existencia de dinámicas de aproximación a Picasso anteriores a 1932 -año en que $G A$ comenzaba su andadura- presentes en la literatura y hemerografía canarias. A partir de esta hipótesis es posible corroborar la influencia insoslayable de revistas como $\mathrm{La}$ Rosa de los Vientos, una de las primeras publicaciones tinerfeñas que dieron voz al cubismo y a Picasso, y en la que destacó el papel de Agustín Espinosa. Además de haber sido decisivo en la apertura de esta nueva ruta, el autor supo incorporar la estética cubista a sus propias obras, y trascendió la comodidad crítica e inició lo que podría considerarse una defensa activa del movimiento.

Así, la presencia del cubismo en la producción literaria y ensayística de Espinosa posibilita una doble lectura: la de reivindicación, en aras de la regeneración cultural del país, y la de militancia activa, definida por el uso que hace de la estética de vanguardia, desde la geometrización de Lancelot, $28^{\circ}-7^{\circ}$ al surrealismo imperante en Crimen. Las conexiones con Picasso son evidentes en aquellos textos que dedicó a la defensa de artistas canarios -tal fue el caso de Jorge Oramas o Felo Monzón-, quienes, como el pintor, habían sido soslayados por la oficialidad y por ciertos sectores del aparato crítico nacional. En este sentido, y a diferencia de algunos de sus compañeros y mentores -entre ellos Eduardo Westerdahl, Guillermo de Torre o Ramón Gómez de la Serna-, su reivindicación del malagueño se distancia de la lógica general de mitificación picassiana, bastante común entre los acérrimos defensores del artista, y presente en la obsecuencia manifiesta del ejemplar que $G A$ le dedicó con motivo de la muestra antológica de ADLAN, número en el que, por cierto, Espinosa no participó.

Menos evidente es, quizás, la influencia del malagueño en la estética de Lancelot, $28^{\circ}-7^{\circ}$, cuyo uso podría simplemente responder al resultado de su contacto con los círculos de la experimentación vanguardista, primero de Madrid, y más tarde de París. No obstante, la geometrización literaria de la geografía de Lancelot remite al imaginario presente en la producción picassiana del primer cubismo, y en concreto al paisaje de Horta de Ebro. Algo similar ocurre con el recuerdo de los clowns o Parade, así como con el simbolismo del dado, representación arquetípica del lenguaje plástico picassiano, al tiempo que imagen predilecta del discurso surrealista. En base a la teoría warburiana sobre la posibilidad de relectura de las imágenes a partir de relaciones apriorísticamente invisibles, la proximidad entre los recursos de Espinosa y Picasso permite repensar y proponer nuevas vías interpretativas en la producción del canario. En suma, una revalorización de su obra en clave cubista -analizada a través del prisma de la historiografía picassiana-, que se vio tristemente interrumpida por su prematura muerte el invierno de 1939. 


\section{BIBLIOGRAFÍA}

Aznar Soler, Manuel (2010): República literaria y revolución (1920-1939), Sevilla: Editorial Renacimiento.

Bonet, Juan Manuel (1997): «Noticias de la zona centro», en Emmanuel Guigon (com.), Gaceta de Arte y su época (1932-1936), Las Palmas de Gran Canaria: Centro Atlántico de Arte Moderno, Viceconsejería de Cultura y Deportes del Gobierno de Canarias, 259-265.

Bravo Ruiz, Natalia (2003): Picasso y la crítica de arte en España (1900-1936), Málaga: Fundación Pablo Ruiz Picasso, Servicio de Publicaciones de la Universidad de Málaga.

Breton, André (1925): «Le surréalisme et la peinture», La Revolution Surréaliste 4: 26-30. URL: https:/gallica.bnf.fr/ark:/12148/cb34381250f/date\#resultat-id-1; 27/12/2019.

Breton, André et al. (1935): Boletín Internacional del Surrealismo 2: 1-9. URL: http://hispanicasuam.es/surrealismo/flippdf/boletin2/mobile/index.html; 15/12/2019.

Cabrera García, María Isabel (2008): "Crítica de arte, ideología y compromiso antes de la guerra civil», en Ignacio Henares y Lola Caparrós (eds.), La crítica de arte en España (1830-1936), Granada: Universidad de Granada, 289-313.

Castro Borrego, Fernando (1978): "Gaceta de Arte y su significación en la historia de la cultura canaria (1932-1936)», Revista de Historia Canaria XXXV: 159-175. URL: https://mdc.ulpgc. es/cdm/singleitem/collection/revhiscan/id/82/rec/9; 7/01/2020.

Domènech, Silvia (2011): «La recepción crítica de la obra de Picasso», en Silvia Domènech (com.), Picasso 1936. Huellas de una exposición, Barcelona: Ajuntament de Barcelona, Institut de Cultura, Museu Picasso Barcelona, 189-200.

Espinosa, Agustín (1927): «De Don Luis de Góngora, en el retorno de su hora poética», La Rosa de los Vientos 2: 11-12.

Espinosa, Agustín (1929): Lancelot, $28^{\circ}-7^{\circ}$. Recogido de J. M. Pérez Corrales (ed.) (2019): Agustín Espinosa. Lancelot, $28^{\circ}-7^{\circ}$. Textos 1927-1929. Agustín Espinosa, Obra en Libertad (19271936), tomo I, 2. ${ }^{a}$ ed., Tenerife: Ediciones Insoladas, 11-114. URL: http://espinosaobraenlibertad.blogspot.com/2019/06/obra-en-libertad.html; 20/02/2020.

Espinosa, Agustín (1933a): Media hora jugando a los dados. Recogido de J.M. Pérez Corrales (ed.) (2018): Agustín Espinosa. Media hora jugando a los dados. Textos 1932-1933. Agustín Espinosa, Obra en Libertad (1927-1936), tomo III, 2. ${ }^{\text {e }}$ d., Tenerife: Ediciones Insoladas, 7-24. URL: http://espinosaobraenlibertad.blogspot.com/2019/06/obra-en-libertad.html; 20/02/2020.

Espinosa, Agustín (1933b): «Toque de diana. Felo Monzón, a $90^{\circ}$ latitud norte», Diario de Las Palmas. Recogido de J.M. Pérez Corrales (ed.) (2018): Agustin Espinosa. Media hora jugando a los dados. Textos 1932-1933. Agustín Espinosa, Obra en Libertad (1927-1936), tomo III, 2. ${ }^{a}$ ed., Tenerife: Ediciones Insoladas, 229-232.

Espinosa, Agustín (1933c): «Ars Republicae», Gaceta de Arte 23: 4.

Espinosa, Agustín (1935): «Navidades de primavera. Breton, Péret y Eluard, nuevos Reyes Magos, en Canarias». La Tarde. Recogido de Emmanuel Guigon (com.) (1997): Gaceta de Arte y su época (1932-1936), Las Palmas de Gran Canaria: Centro Atlántico de Arte Moderno, Viceconsejería de Cultura y Deportes del Gobierno de Canarias 215.

Fernández Hernández, Rafael (2009): «Agustín Espinosa, faro y guía de las Vanguardias Históricas de Canarias", Catharum. Revista de Ciencias y Humanidades del Instituto de Estu- 
dios Hispánicos de Canarias 10: 35-42. URL: https://docplayer.es/37884421-Agustin-espinosa-faro-y-guia-de-las-vanguardias-historicas-de-canarias.html; 26/02/2020.

Francin, Francesc (1981): Picasso y Horta de Ebro, Tarragona: Francisco Francin.

GACETA DE ARTE (1932): «Posición», Gaceta de Arte 1: 1.

GACETA DE ARTE (1935): «Criterio de G.A. sobre el surrealismo que aparecerá en la revista "Cahiers d'Art" París", Gaceta de Arte 35: s/p.

Gasch, Sebastià (1930): «Picasso», La Gaceta Literaria 95: 7.

Giménez Caballero, Ernesto (1928): «Un busto de Cervantes», La Gaceta Literaria 37: 2.

Giménez Caballero, Ernesto (1931): «Fama póstuma. Ante el traslado a Madrid de los restos de Pablo Picasso", La Gaceta Literaria 122: 1-2.

Gómez Alfeo, María Victoria y Fernando García Rodríguez (2009): «Descripción y análisis de las críticas de arte publicadas por la Gaceta Literaria», Documentación de las Ciencias de la Información 32: 25-50.

Gómez de La Mata, Germán (1925): «La verdad sobre Picasso», La Esfera XII: 23.

Gómez de La Serna, Ramón (1936): «El torero de la pintura», Gaceta de Arte 37: 21-24.

Gutiérrez Albelo, Emeterio (1929): «Lancelot, $28^{\circ}-7^{\circ}$. Un libro de Agustín Espinosa», La Tarde. Recogido de J.M. Pérez Corrales (ed.) (2019): Agustín Espinosa. Lancelot, $28^{\circ}-7^{\circ}$. Textos 1927-1929. Agustín Espinosa, Obra en Libertad (1927-1936), tomo I, 2. ${ }^{a}$ ed., Tenerife: Ediciones Insoladas, 293-298.

LA PRENSA (1932): «El número 7 de "Gaceta de Arte" y su manifiesto sobre arquitectura», La Prensa XXII: 2. URL: https://h3.bbtk.ull.es/pandora/cgi-bin/Pandora.exe; 09/01/2020.

HESPÉRIDES (1928): «La editorial HESPERIDES», Hespérides: Artes, ciencias, literatura y deportes 113: 7. Jackson, Rafael (2003): Picasso y las poéticas surrealistas, Madrid: Alianza Editorial.

Lipton, Eunice (1976): Picasso's Criticism: 1901-1939. The Making of an Artist-Hero, Nueva York: Garland.

López Torres, Domingo (1932): «Picasso: cubismo», Gaceta de Arte 7: 1.

MaÑERo Rodicio, Javier (2013): «Acción surrealista y medios de intervención. El surrealismo en las revistas, 1930-1939», Anales de Historia del Arte 23: 209-258. URL: https://doi.org/10.5209/ rev_ANHA.2013.v23.43610; 15/01/2020.

Marquina, Rafael (1930): «Una iniciativa de Cosmópolis», Cosmópolis 4: 33-34. URL: http://www. memoriademadrid.es/buscador.php?accion=VerFicha\&id=149564\&num_id $=\overline{48 \text { num_tot }}$ al=43;07/05/2018.

Mateo Díaz, José (1933): «Agustín Espinosa, jugador de dados», La Provincia. Recogido de J.M. Pérez Corrales (ed.) (2018): Agustín Espinosa. Media hora jugando a los dados. Textos 19321933. Agustín Espinosa, Obra en libertad (1927-1936), tomo III, 2. ${ }^{a}$ ed., Tenerife: Ediciones Insoladas, 259-261.

Matsuda, Kenji (2002): «La imagen de Picasso dentro y fuera de España durante los años treinta», en Miguel Cabañas Bravo (ed.), El arte español fuera de España: XI Jornadas de Arte, Madrid: Consejo Superior de Investigaciones Científicas, 619-632.

Morris, Cyril Brian (1979): «El surrealismo de Tenerife», Revista Iberoamericana XLV: 343-349. URL: https://doi.org/10.5195/reviberoamer.1979.3379; 01/03/2020. 
Nuez, Sebastián de la (1977): La Rosa de los Vientos. Estudio preliminar, Las Palmas: Excelentísima Mancomunidad de Cabildos de Las Palmas.

Palenzuela, Nilo (1991): «El proceso de las revistas: de La Rosa de los vientos a Índice», Atlántica: revista de las artes 2-3: 24-31.

Palenzuela, Nilo (2001): «Encrucijadas del surrealismo: el surrealismo en Canarias», en Jaime Pont (ed.), Surrealismo y literatura en España, Lleida: Edicions de la Universitat de Lleida, 157-179.

Pérez Alfonseca, Ricardo (1934): «El españolismo de Picasso. A propósito de "Picasso et ses amis" de Fernande Olivier», Gaceta de Arte 28: 4.

Pérez Corrales, José Miguel (2019): «Agustín Espinosa: Lancelot, $28^{\circ}-7^{\circ}$ y otros escritos de los años 20", en J.M. Pérez Corrales (ed.), Agustín Espinosa. Lancelot, $28^{\circ}-7^{\circ}$. Textos 19271929, Agustín Espinosa, Obra en libertad (1927-1936), tomo I, 2. ${ }^{a}$ ed., Tenerife: Ediciones Insoladas, 305-352.

Pestana, Ernesto (1927): «Juan Gris», La Rosa de los Vientos 4: 15.

Pestana Ramos, Óscar (1932): «Picasso: primera época», Gaceta de Arte 7: 1.

Robles Tardío, Rocío (2011): Picasso surrealista, Barcelona: Ediciones de la Central.

Rodríguez Doreste, Juan (1965): «Las revistas de arte en Canarias», El Museo Canario XXVI: 47-103. URL: http://www.elmuseocanario.com/images/documentospdf/revistaelmuseo/ Revistas/1965.pdf; 15/02/2020.

Torre, Guillermo de (1933): «Un falso balance del arte nuevo», Revista de Occidente 119: 230-240.

Torre, Guillermo de (1936): «Apología del cubismo y de Picasso», Gaceta de Arte 37: 31-57.

Trueblood, Alan S. (1989): «Góngora visto por Picasso», en Sebastian Neumeister (ed.), Actas del IX Congreso de la Asociación Internacional de Hispanistas (18-23 agosto 1986), Berlín, Frankfurt Main: Vervuert, 655-663.

Tusell, Genoveva (2017): El Guernica recobrado: Picasso, el franquismo y la llegada de la obra a España, Madrid: Cátedra.

Westerdahl, Eduardo (1932): «Picasso: periodo monstruoso», Gaceta de Arte 7: 2.

Westerdahl, Eduardo (1934): «Croquis conciliador del arte puro y social», Gaceta de Arte 25: 2.

Westerdahl, Eduardo (1935): «Arte moderno en Tenerife», La Prensa XV: 1. URL: https://h3.bbtk. ull.es/pandora/cgi-bin/Pandora.exe; 09/01/2020. 
